\title{
Sexual and Reproductive Health Challenges of female-headed Households, a Qualitative Study in Iran
}

TAGHIZADEH Z ${ }^{1}$, KHOSHNAM RAD M ${ }^{2 *}$

${ }^{1} \mathrm{PhD}$ in Reproductive Health, Associate Professor of Tehran University of Medical Sciences, School of Nursing and Midwifery. Tehran, Iran. ${ }^{2} \mathrm{PhD}$ Candidate in reproductive health, Tehran University of Medical Science, School of nursing and midwifery, Tehran, Iran, A member of midwifery group, Alborz University of Medical Science, Karaj, Iran.

- Correspondence to Mahsa khoshnam Email: m-khoshnamrad@razi.tums.ac.ir, Tel: 09360946374 (ORCID ID: 0000-0001-5353-0556)

\begin{abstract}
Background: Female-headed households are families in which the female is the main provider in the household. The reproductive and sexual health needs of women heads of households have been marginalized due to the high pressures that they endure.

Aim: To investigate the Iranian female-supported households' sexual life challenges.

Materials: This study was a qualitative study with the content analysis approach that was done amongst women head of household in Alborz, Iran. Sixteen married females participated and were interviewed deeply in a 7 months period in 2020. All interviews were tape-recorded and transcribed in verbatim. Data were collected and recorded and were encoded, then transcript and analyzed.

Result: Females recruited in this study were of different socioeconomic levels. On average they have been lived 5 years with their husbands. Five key themes were extracted including unmet sexual needs, role conflict, concern about sexually transmitted diseases, unrestrained sexual activity due to irresponsibility of husbands, and sexual abuse from others under the guise of support.

Conclusion: From the results, it could be concluded that not only the reproductive health needs of these women not met, but also these women's sexual life are associated with worry, threats, and discrimination. This requires serious measures to be taken by the authorities and policymakers.

Keywords: Female-headed households, Challenges, Reproductive health, Qualitative study.
\end{abstract}

\section{INTRODUCTION}

One of the important aspects of women's health is reproductive health, and sexual health is one critical pillar of this ${ }^{1}$. The importance of sexual health is obvious to everyone $^{2,3}$. Women's sexual health is directly and indirectly affects the society health. Therefore, having a healthy and satisfying sexual life is an important issue. Healthy sexual relations are directly associated with the quality of matrimony and quality of life ${ }^{4}$. On the contrary, inappropriate sexual relation is one of the principal causes of divorce, societal problems, and psychological diseases and insecurity of the family ${ }^{5}$.

Besides all aspects of sexual health, sexual relation of women in reproductive age is connected to important issues including safe motherhood, unwanted pregnancy, adolescent's pregnancy, abortion and Sexually transmitted diseases ${ }^{6}$.

Although, healthy sexual life under marital condition result in strengthens family functioning and relational bond, in some family's structure, including female-headed families, sexual health have been neglected ${ }^{7}$. The term "female- headed families" is used to refer a family in which the woman is solely responsible for running the "family's expenses and does not have the support of her husband. This lack of support often occurs following a spouse's addiction, death or disability, unemployment, being in prison, or lack of moral or financial competence so he can no longer play a good role in their family structure ${ }^{8}$.

In the last decades, the number of households headed by women has been increased around the world ${ }^{9}$. Female head households are more likely to encounter deprivation and hardships. Poverty and the feminization of poverty theory are the most addressed issues for these families in the literature, but they are suffering from various problems and enduring a lot of pressure ${ }^{10-13}$. Children's custody and care, affording daily life's subsistence and providing housing, taking on the paternal role in addition to being a mother, and keeping family peace are some of the imposed responsibilities to them. Thus, it is not out of expectation that these women are not paying enough attention to themselves, and different aspects of their health, including their sexual needs stays out of the sight ${ }^{14,15}$. According to studies women who live without the support from their husbands have obvious limits in accessing sexual and productive care ${ }^{16,17}$. Because of their improper life state, they feel that talking about their sexual needs is a taboo; they even sometimes think that having sexual relations and sexuality is not their right. Although female-headed households experience many risk factors affecting their sexual life, few studies have been done on this topic ${ }^{3}$.

About 3 million families in Iran are female-headed households, and they are facing different social, economic, and health challenges ${ }^{7,8}$. Most of these women live alone (divorced, widowed, or never married); however, about $10 \%$ have a spouse with them. Although more attention has been paid to these women in recent years, there are still many unexplored dimensions to the health of femaleheaded households ${ }^{9}$. This study was performed to discover sexual needs and challenges of these women in Iran. Hearing their voices and discovering their challenges might be a step ahead to improve their health and family relations. 


\section{MATERIALS AND METHODS}

Design: This study is a qualitative study with content analysis approach that conducted aim to comprehend sexual needs and challenges of female-headed families living with their husbands. A qualitative approach has been chosen as achieving these women's experiences is not convenient with a qualitative analysis. The research received ethical approval (R.TUMS.VCR.REC.1395.280) from Tehran University of medical Science.

Setting and participant: This study was carried out in Iran, Alborz province. Alborz Province is situated $35 \mathrm{~km}$ west of Tehran. Alborz is an immigrant city and its population has increased rapidly in recent years.

For selecting participants a charity and social work center was participated to contact these women. The aim of social work centers is supported from vulnerable groups and enabling them to solve their own problems.

Women who lived in Alborz and aged between 15 to their husbands at least one year, while their husbands were unsuitable (addicted, disabled, imprisoned, ill, or without moral competence; and were unable to afford life's expenses). Women who did not consent to participate in the study were excluded from the study.

To increase the reliability of data, sampling was done purposefully to include maximum possible diversity. After being informed of study procedures and aims, and giving their written informed consent study's subjects were 60 years old were included in this study; if they lived with

interviewed in person. The interviews were done in a comfortable place for participants including a quiet room in the clinic, in their house, or in a public park near their home.

Researcher explained about sexual and reproductive concept to participants and conducted semi structure interview whit them. The Main Questions in Semi structured Interviews were "Please tell me a little about your background and sexual life", "What are your perceptions of the sexual life in your family and with your husband?", "How is your experience of having sex with your spouse?", "What sexual challenges do you think your friends or people with similar conditions experience?" and continued with exploratory questions. Interviews took 60 to 90 minutes in average. Interviews and sampling continued to saturation point (until nothing new came out of the information provided).

Data analysis: With their consent, interviews conducted and were recorded, then transcript and finally entered in MAXQDA software program. The researcher read the transcriptions for several times to have an overall concept of internal and external elements. This is followed by word by word analysis and coding. Then codes classified based on similarities and differences according to the study aims. Finally principal themes were extracted from interviews.

\section{RESULTS}

\begin{tabular}{|c|c|c|}
\hline Variable & categories & Number \\
\hline \multirow[t]{3}{*}{ Age (years) } & $18-30$ & 5 \\
\hline & $31-50$ & 10 \\
\hline & $50>$ & 1 \\
\hline \multirow[t]{4}{*}{ Parity } & None & 4 \\
\hline & One & 3 \\
\hline & 2 & 3 \\
\hline & 3 and More & 6 \\
\hline \multirow[t]{5}{*}{ Educational level } & Illiterate & 1 \\
\hline & Middle school & 3 \\
\hline & High school diploma & 9 \\
\hline & Academic & 3 \\
\hline & Total & 16 \\
\hline \multirow{5}{*}{ Length of life with spouses (Year) } & $1-5$ & 3 \\
\hline & $5-10$ & 4 \\
\hline & 10-15 & 2 \\
\hline & $15-20$ & 7 \\
\hline & Total & 16 \\
\hline \multirow{8}{*}{ Spouses' problem } & Disabled & 3 \\
\hline & Addicted & 2 \\
\hline & Mentally ill & 2 \\
\hline & Wife beater, Bad temperate & 4 \\
\hline & Sybaritic and extramarital sex & 1 \\
\hline & Veteran injury & 1 \\
\hline & Other & 3 \\
\hline & Total & 16 \\
\hline \multirow[t]{6}{*}{ Women's job } & Unemployed & 8 \\
\hline & Clerk, secretary & 2 \\
\hline & Tailor, barber, & 3 \\
\hline & Street vendor, Seller & 1 \\
\hline & Home nurse & 2 \\
\hline & Total & 16 \\
\hline \multirow[t]{5}{*}{ Household income } & Very poor (Only under the support of State Welfare Organization) & 5 \\
\hline & Poor & 6 \\
\hline & Moderate & 3 \\
\hline & Good (without financial problem) & 2 \\
\hline & Total & \\
\hline
\end{tabular}


Samples aged between 18 to 57 years with the average of $33.68 \pm 2$ years. They have different lived experiences, different socioeconomic, and education levels. Women lived with their unsuitable spouses for an average of $5 \pm 0.1$ years. Table 1 lists the participant's demographic characteristics (Table 1).

After the analysis of extracted codes five themes were separated including unmet sexual needs, gender role conflict in sexual life, concern about sexually transmitted diseases (STD), unrestrained sexual activity and irresponsibility of husbands, and sexual abuse from others under the guise of support.

\section{Unmet sexual needs}

Suppressing libido: The women stated that their relationship was no longer the same as before (when their spouse was headship of the family). Subjects said that they are not satisfied with their current sexual relations. They declare negative experiences about sexual relationship that was vary from coldness in sex or decreased quality and quantity of sex to completely not having sex.

Participant 3: "when you are with him, there is no desire, nothing, from beginning to end. I think his relations are completely useless. I have sexual needs. I want him to embrace me and sleep with me. But now, we sleep separately in different rooms."

It is difficult for these women to cope with this unmet need so that they become disappointed and depressed.

Participant 16: "long after marriage, sex is still needed. No one could say that after years you not anymore need sex. I still have sexual needs, and the pressure of these unmet needs made me depressed."

Participant 4: "I'm a woman too. Sometimes I have sexual needs. So, I would take a cold bath. What widows do in the past? They don't have separate rooms, and when their husband dies, they live with their mother-in-law. They finally suppressed their needs too.

\section{Staying for the children}

Even if they don't know how to, women with bad spouses try to make their relations better. Some of their attempts included increasing their kindness to the spouses, forgetting their own needs, endurance, and increased attention to their children.

Participant 1: "I give him a lot of chances. I increased my affection. I have his back. I say to myself that he is involved in problems. I should pay more attention to him. Perhaps he also pays attention to me and shows his love. I have to tolerate more."

Participants of this study face the dilemma of raising their 1children or paying attention to their sexual needs and having children was a hurdle for divorce.

Participant 9: "I don't know happiness comes from giving my daughter's custody to her father and marry again or raising her myself. I have marriage proposals. I have a good suitor. But I cannot decide."
Gender role conflict in sexual relation: Even though women were the heads of the household, men still played a dominant role regarding sexual relations. The changes in the roles of such families made interpersonal and sexual relations complex. Females may ignore their husband's sexual needs because of concerns about the future.

Participant 10: "When all the hard work of life is on my shoulders, from morning to night, is there a time or rationale for sexual relations? If I get pregnant, who is supposed to pay for necessities? How do I raise the baby? Is there any support for me if I have a miscarriage or get sick?"

Forced sex: Women complained about being forced into forced sex. Sex without desire, hate and dislike for spouse sex, and spouse sexual violence are some of the issues that subjects noted.

Participant 7: "I don't understood sex. If he wanted, we had sex. If he didn't, we don't. It was never to my desire."

Concern about sexually transmitted diseases: Concern about STDs was mentioned by the majority of participants (15 of 16). This was an important issue among other themes.

\section{Lack of knowledge of sexually transmitted diseases}

Almost all of the participants were concerned about STDs and HIV. This was mentioned even by women with no sexual relations with their husbands. Awareness about STDs was one of the major needs of these women.

Participate 16: "I do not know much about these things. How many times and when should I have a test for such diseases? My husband was a prisoner; does it mean that I need to be tested? How sexual diseases are transmitted, and how are prevented? Honestly, I do not have much information about them."

\section{Inaccessibility of health services}

Most of the participated women stated that they need to be provided with the facilities for sexual laboratory tests and examinations and need to physician or midwife's visits.

Participant 11: "It will be a good thing for us if the State Welfare Organization could bring us a good gynecologist, and we could have a check-up. Because of fear of diseases like HIV, one fears having sex with somebody"

Participant 8: "There is no place for us. It is not culturally acceptable for a woman who is not living with her husband to become pregnant or consult about her worries about sexually transmitted diseases. Also, these centers are expensive, and their services are not covered by insurance. One gets ill, also humiliated, and even cannot tell anyone about this."

Unrestrained sexual activity and irresponsibility of husbands

Sometimes being a bad spouse means that men have sexual relation outside the marriage. Wives who their husbands have multiple partners feel helpless and emotionally overwhelmed especially if their husbands are addicted.

Participant 16:"The police officer opened it up for me. He told me that because of substance abuse, his blood amphetamine level is several times more (I think 200 to 2000) than others. Thus, he doesn't enjoy enough and needs to have sex again and again."

Anger against spouse 
Most of the women were angry about their condition and cannot forgive their husbands. Anger towards the husband affects a woman's decision about sex and childbearing. Participant 13: "He seeks sex diversity. And his family knows that he has some adulterous relationship and advised him. I'm a woman. If I am the problem, why he has sex with many other women and was not satisfied with one?" My problem is that everybody knows, and it is obvious now to all. But he has no desire to fix it and doesn't want to correct himself."

Participant 12: "If I can, I'll kill him! I will choke him with my own hands!"

2- Sexual abuse from others under the guise of support 'Abuse by strangers' and 'harassment by familiar people' were the two sub-themes that forms "sexual abuse from others under the guise of support" theme. Some of women stated that when they go alone to offices or stores for daily needs, they feel insecure because some employees offered them financial and emotional support in the exchange of sex. It causes more stress and isolation for these women. Regardless of the risk from strangers, women also felt to be at risk even in the family context.

Participant 4: "He said: "look, I know your husband does not support you. I can be your friend and support you. Whatever you want, in whatever way you say. Your husband couldn't support you. You finally need one, count on me."

Participant 3: "For example, now there is a man, we are not living with each other, but he supports me completely. That means I get money from him every week. We still have no relationship. But he said "I'll buy you a store and I will come to sleep with you twice a month. I need you, maybe you don't need me. I support you all." Nevertheless, he hasn't even touched me so far."

\section{DISCUSSION}

The results of this study showed that when husbands of these women lose their competence as a good husband (because of addiction or disability), the quality of sexual relations change. This usually associated with negative experiences with sex. These negative experiences can vary from coldness in sex or decreased quality and quantity of sex to completely not having sex. In accordance with other studies, women who participated in this study tried to adapt to their conditions. Nilsson and et al said to cope with changes in sexual life isn't easy for women that similar with our study in women sense of depression and disappointment. However, they think that do not supposed to have sexual relations in their life. They feel that from society's perspective, having sex is not justified for them anymore $^{3}$, and these women gradually eliminate sex from their life.

In the present study, many women said that their decreased their libido by trying to increase their attention to their children future. In the other studies, suppression of libido and self-restraint, decreasing invests in a new mating relationships and diminishing sexual thoughts was reported $3,4,17$. Women were reluctant to enter a new sexual life (remarriage) because of their children and did not want to oppress them. It was not surprising that a lot of women devote themselves to strengthen their family and children.
Gray et al. concluded from their study that only a small number of women with little children would enter a new sexual relationship. These women have more limited energy and time to initiate a new relationship. And they direct their attention and time to their children ${ }^{17}$.

The results of this study showed that having bad experiences of relationships for these women is not equal to hating their husbands. At some point in life, any woman may face her husband's addiction, illness, disability or unemployment. As participates said disintegration of life is the first thing that comes to mind, but it is not the solution for all of the participants.

The second theme that emerged from this study was gender role conflict about sexual needs. Even though women were the heads of the household, their husbands would decide on their sexual health needs, relationship, and contraception use. Unmet needs, the dissatisfaction of each other, and unavailability of the spouse may compromise the quality of sexual relations, and sometimes sexual life of a female-headed household was accompanied by domestic violence, sex without the desire of women, or verbal threats ${ }^{18,19}$. Male dominance in the traditional structure, gender inequality ${ }^{18,20}$, men's inability to perform their role, and the resulting nervous pressure are some of the reasons for violence against women ${ }^{5}$. Force sex can be associated with STD, HIV, unwanted pregnancies, decreased libido, and chronic pelvic pain ${ }^{21,2}$. It is also can cause psychological trauma and torment for these women. These can lead to hate of having sex with their husbands.

One of the most important women's concerns was about sexually transmitted diseases (STD). Awareness about STDs, screening, and physician or midwife's visits were one of the major needs of these women. Most of the participated stated that they need to be provided with the facilities for sexual laboratory tests and examinations.

Safe conditions must be provided for women to express their sexual needs. Enough time should be allocated for examination, diagnosis, and treatment of their possible STDs. Allocating time by healthcare providers, providing services tailored to the needs of this specific group, paying attention to their unmet needs, and having a holistic view of these sexual problems is essential, but unfortunately not included in current health care programs ${ }^{3}$. Regarding the association between STDs and human immune deficiency virus (HIV), education on safe sex is recommended. It is especially important for vulnerable populations such as addicted husbands, homeless women, and those with improper socioeconomic status, as they are at risk of forced $\operatorname{sex}^{20}$.

The issue of the spouse's irresponsibility in marital relations in the family shows the experience of unfaithfulness on the part of the wife puts a great deal of emotional distresses for women. It could also be associated with harms. Loss of trust, the breakup of marital relations, and psychological problems are just some of these harms. Infidelity can even give rise to familicide ${ }^{18}$. Females with addicted husbands are more at risk of sex diversity. Thomas's study on gambler men showed that addiction influences their personality and behavior. It also reduces the sense of sexual satisfaction. These men need to have more sexual relations, and their satisfaction is less 
than healthy men ${ }^{22}$. Several studies have shown that addiction and substance abuse have adverse effects on sex life. Yang et al. found that, unlike addicted men, HIV infected men had more commitment to their wives, and they had less out of the marriage sexual contacts. They had limited their sexual relations and paid more attention to their wives' satisfaction, as they were concerned about partner health ${ }^{23}$. As revealed in last emerged themes of study, some women with bad spouses experienced dealing with men with unconventional offers such as sex for financial or emotional support. This issue and fear of sexual victimization diminish their social security and activity. Thus, the social roles of these women will become more restricted, and some secret relationships will be formed ${ }^{11}$. Sometimes women resort to prostitution to make a living. Della noted economic necessity, lack of job skills, and unwilling to abandon children are among the causes of prostitution ${ }^{15}$. But in Islam and Iranian culture, sex has been restricted to married men and women, and adultery has been forbidden and these behaviors were not acceptable 24,25 .

This study tried to explain the sexual challenges of women who do not have good support from their husbands and sought to discover their problems and challenges. Most of the studies in this field focused on single mothers, singlehood, widowhood, and divorce or living separated ${ }^{9}$. Studies about women with unsuitable husbands are scant. Women who live with their bad (irresponsible) spouses have not studied well, and there is not a clear definition in the literature addressing this population. This study was noble in this respect. Paying attention to these women's challenges is necessary, and planning to meet their needs as a reproductive health priority is essential. Further studies about planning for the provision of sexual health care of female-headed households are suggested.

\section{CONCLUSIONS}

Based on what has been discussed, it can be claimed that female-headed households are deprived and oppressed, and their sexual health needs are not addressed. On the other hand, they are so involved in earning a livelihood that they do not seek help, and they are also ashamed of expressing their health needs especially sexual needs. It is the healthcare team's duty to provide consultation and visit them. It seems to be helpful to allocate time for them in clinics for sexual health consultations. The unanswered concerns of these women, in addition to themselves, lead to the dissolution of their families, the families and children that these women protected them wholeheartedly. In this case, the only delight for their children, seeing the loving smile of their mother despite all the exhaustion and despair, will be unattainable.

Limitations: In this study, the women were from a vulnerable population, and their sexual challenge is a sensitive issue. It is somewhat difficult to access, consent to study, and talk about their sexual problems. Responses may have been subject to social-desirability bias. We used the best- friend technique to mitigate this bias. Economic problems were their main challenges of health. Talking about something other than financial challenges and problems was not easy and required extra effort and extensive interviews.

Suggestions: Listening and trying to understand their problems, providing conditions for medical examinations regarding their sexual health, establishing family consultation centers, consulting their husbands, and societal and financial supports are some of the suggested solutions for this females and their families.

Acknowledgement: We would like to thank the individuals who generously greed to participate in this study and shared their time, experience, and materials for the purposes of this work.

Conflict of interest: The authors have no conflicts of interest to declare.

Funding : This work was supported by the Tehran University of Medical Science, Faculty of Nursing and Midwifery. Grant number: R.TUMS.VCR.REC.1395.280

\section{REFERENCES}

1. Kling JM, Faubion SS, Kapoor E. Sexual Health in Women. Journal of Women's Health. 2021;30(3):301-4.

2. Brotto L, Atallah S, Johnson-Agbakwu C, Rosenbaum T, Abdo C, Byers ES, et al. Psychological and interpersonal dimensions of sexual function and dysfunction. The journal of sexual medicine. 2016;13(4):538-71.

3. Nilsson Ml, Fugl-Meyer K, von Koch L, Ytterberg C. Experiences of sexuality six years after stroke: a qualitative study. The journal of sexual medicine. 2017;14(6):797-803.

4. Rashidi BH, Kiyani K, Haghollahi F, Sighaldeh SS. Sexual health definition from the perspective of Iranian experts and description its components. Tehran University Medical Journal. 2015;73(3).

5. Kahn NF, Halpern CT. Experiences of vaginal, oral, and anal sex from adolescence to early adulthood in populations with physical disabilities. Journal of Adolescent Health. 2018;62(3):294-302.

6. Mbizvo M. Reproductive and sexual health: a research and developmental challenge. The Central African journal of medicine. 1996;42(3):80-5.

7. Lebni JY, Gharehghani MAM, Soofizad G, Irandoost SF. Challenges and opportunities confronting female-headed households in Iran: a qualitative study. BMC women's health. 2020;20(1):1-11.

8. Afrasiabi $\mathrm{H}$, Jahangiri $\mathrm{S}$. Problems of social interactions of women head of household (Qualitative study amongst ShahinShahr women). Women in Development \& Politics. 2016;14(4):431-50.

9. Liu C, Esteve A, Treviño R. Female-headed households and living conditions in Latin America. World Development. 2017;90:311-28.

10. Veisani Y, Delpisheh A, Sayehmiri K. Health related quality of life in the female-headed households. International Journal of Epidemiologic Research. 2015;2(4):178-83.

11. Kotwal N, Prabhakar B. Problems faced by single mothers. Journal of Social Sciences. 2009;21(3):197-204.

12. Bradshaw S, Chant S, Linneker B. Challenges and changes in gendered poverty: The feminization, de-feminization, and refeminization of poverty in Latin America. Feminist Economics. 2019;25(1):119-44.

13. AbdelLatif LM, Ramadan M, Elbakry SA. How gender biased are female-headed household transfers in Egypt? Middle East Development Journal. 2019;11(2):165-80.

14. Clark S, Madhavan S, Cotton C, Beguy D, Kabiru C. Who helps single mothers in Nairobi? The role of kin support. Journal of Marriage and Family. 2017;79(4):1186-204. 
15. Dalla RL. Exposing the "pretty woman" myth: A qualitative examination of the lives of female streetwalking prostitutes. Journal of Sex Research. 2000;37(4):344-53.

16. Buvinić M, Gupta GR. Female-headed households and femalemaintained families: are they worth targeting to reduce poverty in developing countries? Economic development and cultural change. 1997;45(2):259-80.

17. Gray PB, Garcia JR, Crosier BS, Fisher HE. Dating and sexual behavior among single parents of young children in the United States. The Journal of Sex Research. 2015;52(2):121-8.

18. Kamali S, Ameri F, Khosravi Z, Ramezani M. Lived experience of women of their husbands' extramarital relationships: A phenomenological study. 2018.

19. Holcombe E, Manlove J, Ikramullah E. Forced sexual intercourse among young adult women: Child Trends; 2008.

20. Fawzi MS, Lambert W, Singler J, Tanagho Y, Leandre F, Nevil $P$, et al. Factors associated with forced sex among women accessing health services in rural Haiti: implications for the 26. $13-25$ prevention of HIV infection and other sexually transmitted diseases. Social science \& medicine. 2005;60(4):679-89.

21. Puri M, Tamang J, Shah I. Suffering in silence: consequences of sexual violence within marriage among young women in Nepal. BMC public health. 2011;11(1):29.

22. Tomasz W, Kowalczyk R, Lew-Starowicz Z. The quality of sexual life and personality of men addicted to gambling. Seksuologia Polska. 2018;16(2).

23. Yang Y, Lewis FM, Wojnar D. Life changes in women infected with HIV by their husbands: An interpretive phenomenological study. Journal of the Association of Nurses in AIDS Care. 2015;26(5):580-94.

24. Parker L, Riyani I, Nolan B. The stigmatisation of widows and divorcees (janda) in Indonesia, and the possibilities for agency. Indonesia and the Malay World. 2016;44(128):27-46.

25. amid RA, Sanusi IARM. Challenges and negative effects of divorce among Muslim women in Northern Nigeria. Journal of Arts and $\mathrm{H}$ Humanities;2016;5(11): 